\title{
Differential Effect of Solution Conditions on the Conformation of the Actinoporins Sticholysin II and Equinatoxin II
}

\author{
EDSON V.F. FAUTH ${ }^{1}$, EDUARDO M. CILLI ${ }^{2}$, RODRIGO LIGABUE-BRAUN ${ }^{1}$ and HUGO VERLI $^{1}$ \\ ${ }^{1}$ Centro de Biotecnologia, UFRGS, Av. Bento Gonçalves 9500, Caixa Postal 15005, 91500-970 Porto Alegre, RS, Brasil \\ ${ }^{2}$ Universidade Estadual Paulista, UNESP, Instituto de Química, Departamento de Bioquímica e Tecnologia Química, \\ Rua Prof. Francisco Degni, 55, 14800-060 Araraquara, SP, Brasil
}

Manuscript received on June 5, 2014; accepted for publication on August 11, 2014

\begin{abstract}
Actinoporins are a family of pore-forming proteins with hemolytic activity. The structural basis for such activity appears to depend on their correct folding. Such folding encompasses a phosphocholine binding site, a tryptophan-rich region and the activity-related N-terminus segment. Additionally, different solution conditions are known to be able to influence the pore formation by actinoporins, as for Sticholysin II (StnII) and Equinatoxin II (EqtxII). In this context, the current work intends to characterize the influence of distinct solution conditions in the conformational behavior of these proteins through molecular dynamics (MD) simulations. The obtained data offer structural insights into actinoporins dynamics in solution, characterizing its conformational behavior at the atomic level, in accordance with previous experimental data on StnII and EqtxII hemolytic activities.
\end{abstract}

Key words: Actinoporins, GROMACS, Molecular dynamics, Pore-forming proteins.

\section{INTRODUCTION}

Actinoporins are a family of potent pore-forming proteins produced by sea anemones (Cnidiaria: Anthozoa: Actiniaria) (Álvarez et al. 2009, Anderluh and Maček 2002, Bakrac and Anderluh 2010). These toxins are synthesized as stable water-soluble monomers that assemble into oligomeric porelike structures to promote target cell lysis (Álvarez et al. 2009, Mancheño et al. 2001, 2003). Model actinoporins include Sticholysin II (StnII) and Equinatoxin II (EqtxII), obtained from Stichodactyla helianthus and Actina equine, respectively (Kristan et al. 2009, Parker and Feil 2005, Lanio et al. 2001).

Correspondence to: Hugo Verli

E-mail: hverli@cbiot.ufrgs.br
These toxins have a remarkable sequence similarity (higher than 90\%) and present a globular shape with a $\beta$-sandwich fold, flanked by $\mathrm{N}$ - and $\mathrm{C}$-terminal $\alpha$-helices (Mancheño et al. 2003, Hinds et al. 2002, Athanasiadis et al. 2001, Huerta et al. 2001). Their structure and conformation have been studied by different approaches (Norton 2009), including circular dichroism (CD) (Martínez et al. 2001, Poklar et al. 1997), fluorescence measurements (Álvarez et al. 2001, Malavasic et al. 1996), X-ray crystallography (Mancheño et al. 2003, Athanasiadis et al. 2001) and NMR spectroscopy (Hinds et al. 2002) (Figure 1).

In these proteins, three regions were observed to be functionally important in the pore-formation activity in model lipid membranes and in red blood cells. They 
are: the phosphocholine binding site (Ser52, Val85, Ser103, Pro105, Tyr111, Tyr131, Tyr135, Tyr136 in StnII and Ser54, Val87, Ser105, Pro107, Tyr113, Tyr133, Tyr137, Tyr138 in EqtxII), the tryptophan-rich region (Trp110, Trp114, Trp115 in StnII and Trp112, Trp116, Trp117 in EqtxII), and the N-termini (Ala1Ser30 in StnII and Ser1-Ile33 in EqtxII) (Mancheño et al. 2003, Hong et al. 2002, Anderluh et al. 1997).
It is proposed that the phosphocholine binding site is responsible for the recognition of its molecular target and interaction between the Trp-rich region and the lipid bilayers (Mancheño et al. 2003, Hong et al. 2002). Such event is followed by an N-terminal displacement into the lipid bilayer, thought to be mandatory for the functional pore formation (Casallanovo et al. 2006, Kristan et al. 2004).

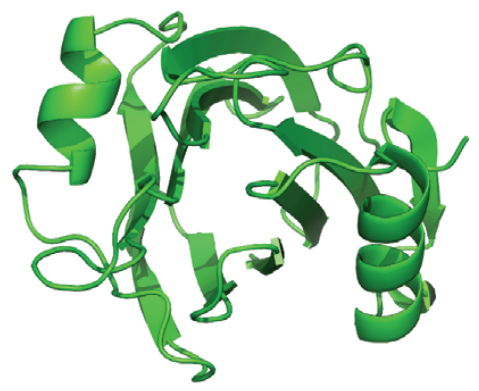

Stnll (PDB : 1GWY)

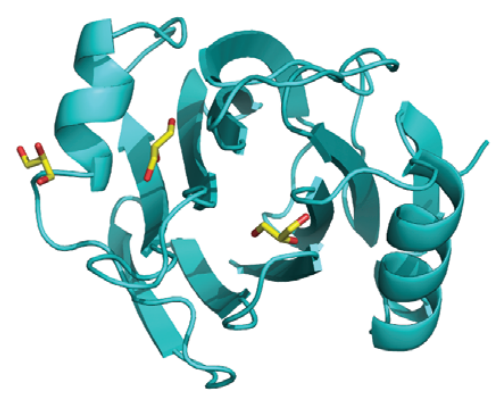

Stnll

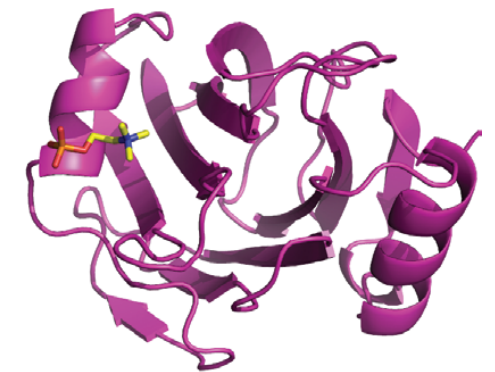

Stnll

(PDB : 1072)

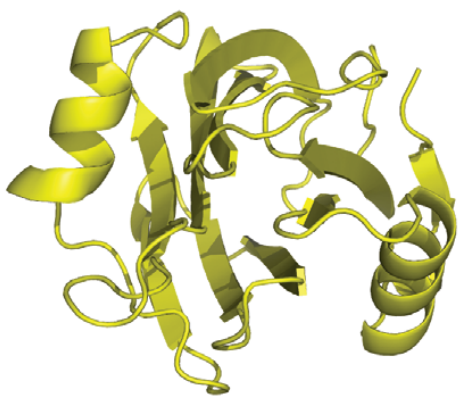

Eqtxll (PDB : 1IAZ)

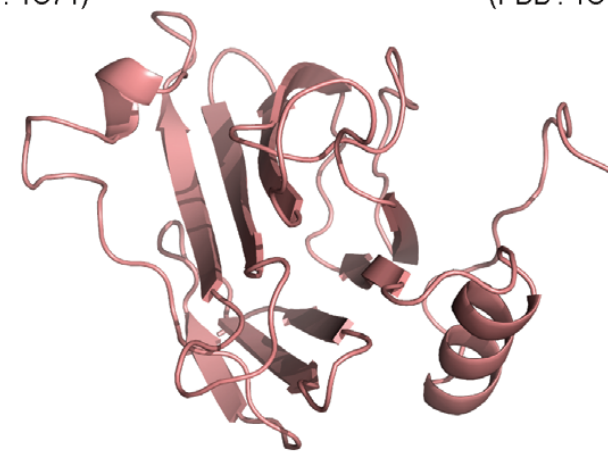

Eqtxll

(PDB : 1KD6)

Figure 1 - Comparison between all atomic structures of actinoporins available. Crystal structure of StnII (PDB ID 1GWY), crystal structure of StnII complex with glycerol (PDB ID 1O71), crystal structure of StnII complex with phosphorylcholine (PDB ID 1O72), crystal structure of EqtxII (PDB ID 1IAZ) and NMR structure of EqtxII (PDB ID 1KD6).

The exposure of StnII and EqtxII to different solution conditions, including urea solutions and different $\mathrm{pH}$ values, affects the hemolytic activity of these proteins, with variable degrees of conformational changes (Ulrih et al. 2004, Álvarez et al. 2001, Mancheño et al. 2001, Martínez et al. 2001, Malavasic et al. 1996). The main conformational differences between NMR and crystal structures of these toxins lie on the C-terminus $\alpha$-helix (Gln128-
Tyr136 in StnII and Gln130-Tyr138 in EqtxII), at the phosphocholine binding site (Álvarez et al. 2009, Miles etal.2008, Hinds etal.2002). Since actinoporins are considered a potential target for biotechnological applications (Tejuca et al. 2009), the current work intends to characterize the dynamics of StnII and EqtxII under distinct physical-chemical conditions as a strategy to gain insights into the structural basis for the actinoporins hemolytic activity. 


\section{COMPUTATIONAL METHODS}

\section{NOMENCLATURE AND SOFTWARE}

The nomenclature guidelines proposed by IUPAC (1970) were used. The molecular dynamics (MD) calculations and analyses were performed using GROMACS simulation suite (van der Spoel et al. 2005) and GROMOS96 43a1 force field (van Gunsteren et al. 1996). The manipulation of structures was carried out with VMD (Humphrey et al. 1996), Pymol (Delano 2002) and Swiss PDB viewer (Guex and Peitsch 1997). The monitoring of secondary structure content was performed by PROCHECK (Laskowski et al. 1993) and ellipticity at $222 \mathrm{~nm}$ was calculated with $g$ _helix tool from GROMACS package, according to Hirst and Brooks (Hirst and Brooks 1994), and plotted using SigmaPlot v.11.

\section{MoleCUlar DyNAMics Simulations}

The crystal structures of actinoporins StnII (PDB ID 1GWY) and EqtxII (PDB ID 1IAZ) were retrieved from Protein Data Bank and the respective monomeric forms were employed in the simulations. Each monomer was solvated in a triclinic box using periodic boundary conditions and SPC water model (Berendsen et al. 1981). Counter ions were added to neutralize the systems whenever necessary. Amino acids ionization was automatically adjusted to $\mathrm{pH}=$ 7.0 or $\mathrm{pH}=3.0$ within GROMACS according to the standard $\mathrm{pKa}$ values of the amino acids side chains. Accordingly, the side chains of residues Asp18, Asp36, Asp56, Asp76, Asp107, Asp116, Asp127, Asp133, Asp143, Glu22, Glu23, Glu38, Glu61, Glu132, Glu148, Glu166, and His147 in StnII, and Asp10, Asp17, Asp38, Asp58, Asp78, Asp96, Asp109, Asp129, Asp146, Glu24, Glu40, Glu134, Glu135, Glu173, His63, His67, His150, His169, and His175 in EqtxII were protonated when in acidic medium with no change to the water model. In neutral $\mathrm{pH}$, these residues are in its non-protonated forms. A solution of 10.0 M urea was also used for StnII simulation (Rocco et al. 2008). The employed
MD protocol was based on previous studies (de Groot and Grubmüller 2001). The Lincs method (Hess et al. 1997) was applied to constrain covalent bond lengths, allowing an integration step of $2 \mathrm{fs}$ after an initial energy minimization using Steepest Descent algorithm. Electrostatic interactions were calculated using the Particle Mesh Ewald method (Darden et al. 1993). Temperature and pressure were kept constant by coupling proteins, ions, and solvent to external temperature and pressure baths with coupling constants of $\tau=0.1$ and $0.5 \mathrm{ps}$ (Berendsen et al. 1984), respectively. The reference temperature was set to $310 \mathrm{~K}$. The systems were slowly heated from 50 to $310 \mathrm{~K}$, in steps of $5 \mathrm{ps}$, each one increasing the reference temperature by $50 \mathrm{~K}$, allowing a progressive thermalization of the systems. Each simulation was then performed for $0.1 \mu \mathrm{s}$, without any restraint.

\section{RESULTS AND DISCUSSION}

\section{SimULATION SySTEMS}

Considering previous experimental results on structure and conformation of actinoporins (Álvarez et al. 1998, 2001, 2009, Miles et al. 2008, Ulrih et al. 2004, Mancheño et al. 2001, 2003, Hinds et al. 2002, Athanasiadis et al. 2001, Martínez et al. 2001, Poklar et al. 1997, Malavasic et al. 1996), six systems were submitted to MD simulations: 1) EqtxII under $\mathrm{pH}=$ 7.0; 2) EqtxII under $\mathrm{pH}=3.0 ; 3)$ StnII under $\mathrm{pH}=$ 7.0 ; 4) StnII under $\mathrm{pH}=3.0$; 5) StnII under $\mathrm{pH}=7.0$ starting from the last frame of the simulation at $\mathrm{pH}=$ 3.0 ; 6) StnII in 10.0 M urea solution. While Systems 1-4 and 6 employed, as their starting geometries, the respective StnII and EqtxII crystallographic structures, System 5 was simulated using the last frame from System 4 as its starting geometry.

\section{SIMULATION STABILITY}

The overall progression of the performed simulations was first assessed by root mean square deviation (RMSD). Each system had their RMSD evaluated taking the respective crystallographic 
structure as reference in function of time (Figure 2). The MD simulations of StnII in physiologic and acidic conditions (Systems 3 and 4, black and blue, respectively) were stable up to $0.04 \mu$ s (Figure 2B). After this period, the deviation from starting structure

A

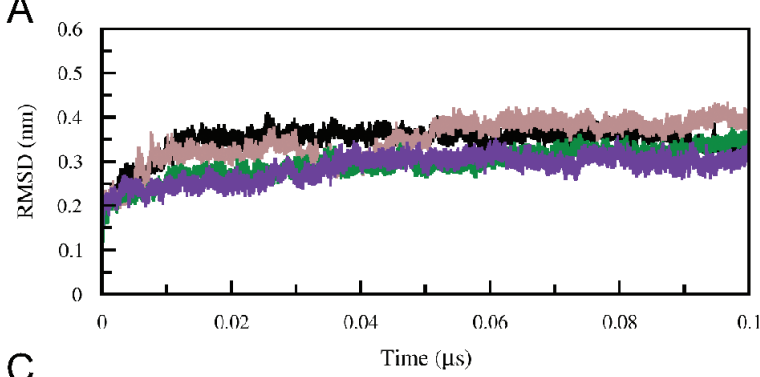

C

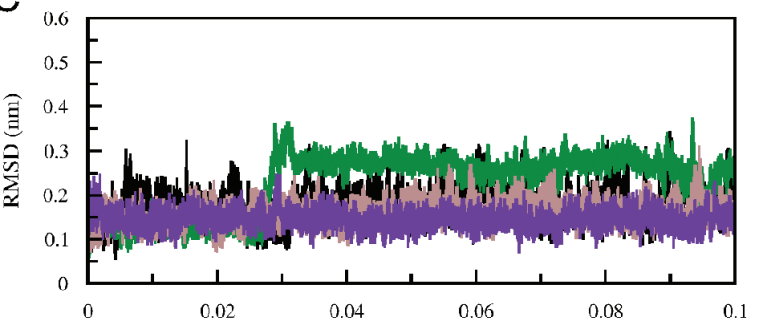

E

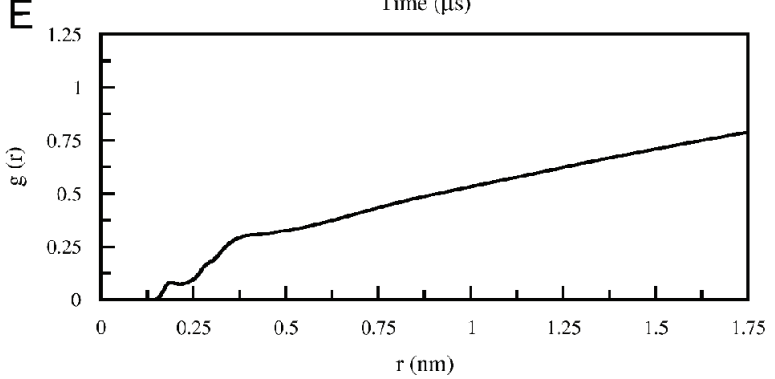

increased under acidic condition. This increase seems to be mainly related to partial unfolding of C-terminal $\alpha$-helix (Figure 2D and Figure 3F). On the other hand, this C-terminal helix on EqtxII seems to be more stable in acidic conditions (Figures 2A, 2C and 3E).

B

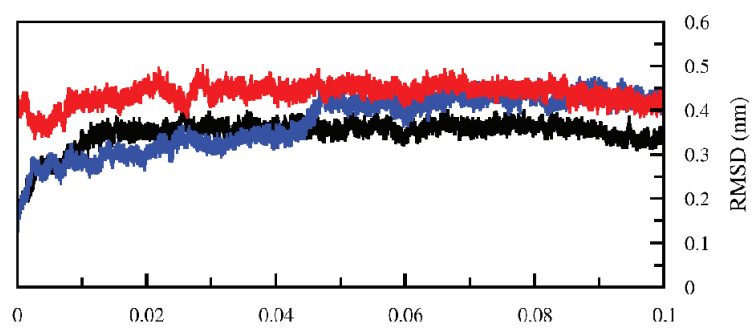

D

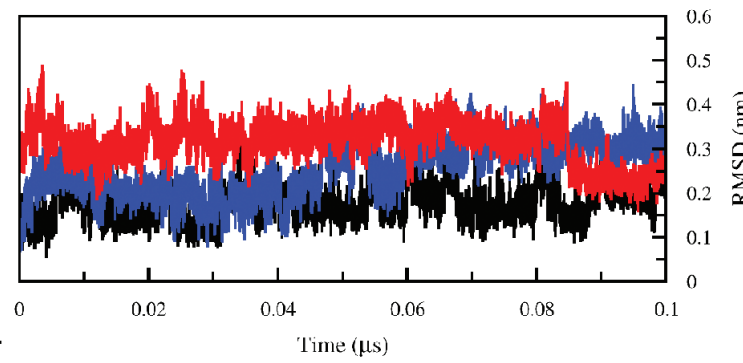

$\mathrm{F}$

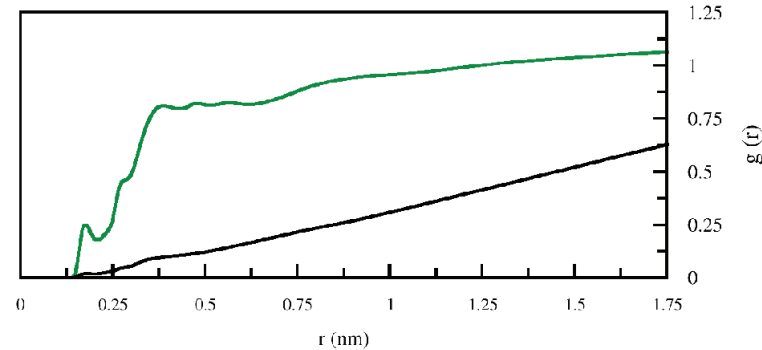

Figure 2 - MD analyses as a function of time for Systems 1 (brown), 2 (indigo), 3 (black), 4 (blue), 5 (red), and 6 (green). All-atom RMSD from crystal structure is shown in (A) and (B) for entire protein, and in (C) and (D) for residues from the C-terminal $\alpha$-helix. A comparative radial distribution function (RDF) of water molecules around StnII in System 3 and System 6 (black curve in E and F, respectively) and urea molecules around StnII in System 6 (green curve in F).

There was secondary structure loss during the trajectory of StnII at $\mathrm{pH} 3.0$, as observed via pseudo dihedral $\xi$ (Figure 3F). Considering this observation and aiming to further explore the influence of $\mathrm{pH}$ on StnII conformational stability, the last frame from the acidic simulation of StnII was used to start a new simulation in neutral $\mathrm{pH}$. During this simulation, the evaluation of the C-terminal $\alpha$-helix RMSD indicated a reoccurrence of the conformation adopted by this helix in pH 7.0 (System 5, red curve in Figure 2D and Figure 3F for the pseudo dihedral $\xi$ ).
This observation, points to the reversibility of the conformational modifications observed for StnII between acidic and neutral solutions.

The highly concentrated urea solution caused an increase of hydrophilic solvent-accessible surface (SAS) for StnII (Figure 4A). Nonetheless, no major difference could be observed for its RMSD (Figure $2 \mathrm{~A}$ ), indicating that, at least in the simulated time scale, these conditions do not significantly affect the protein structure stability, despite the increased C-terminal $\alpha$-helix (Figure 2C). 
A

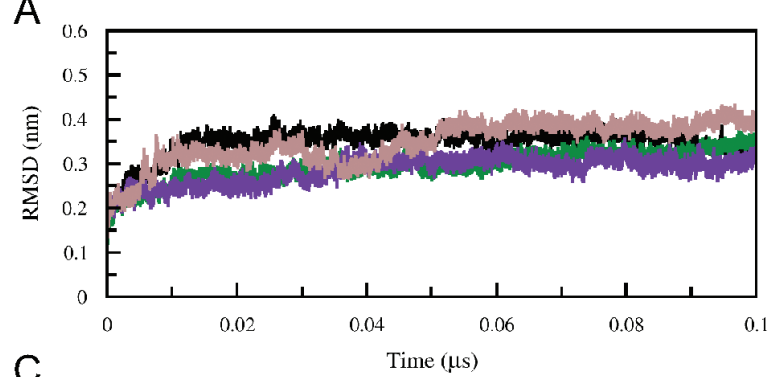

C
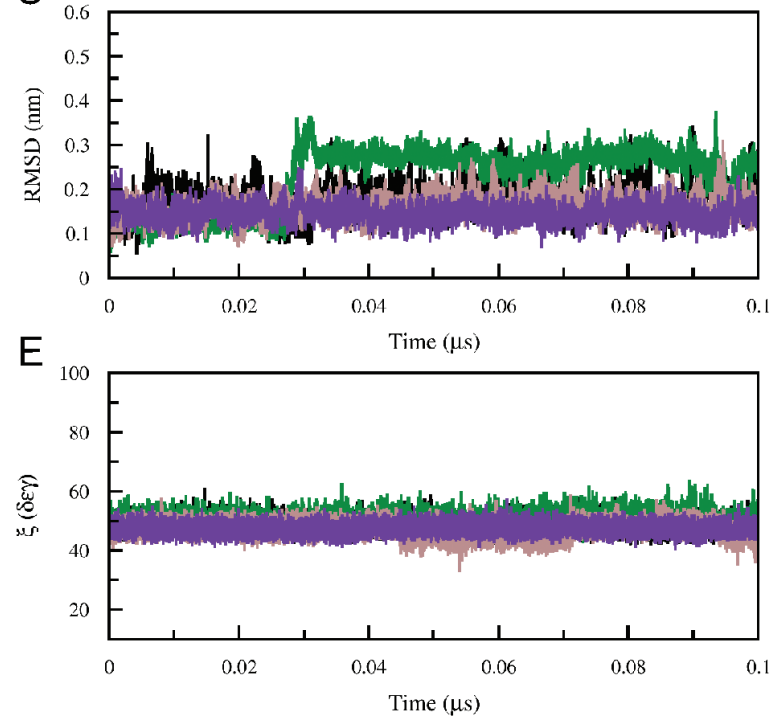

B

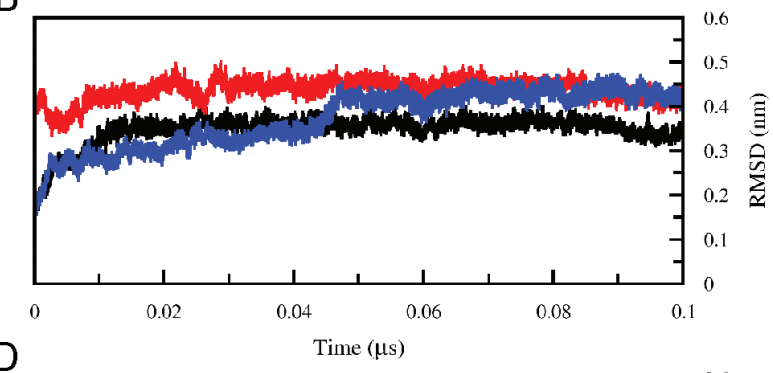

D

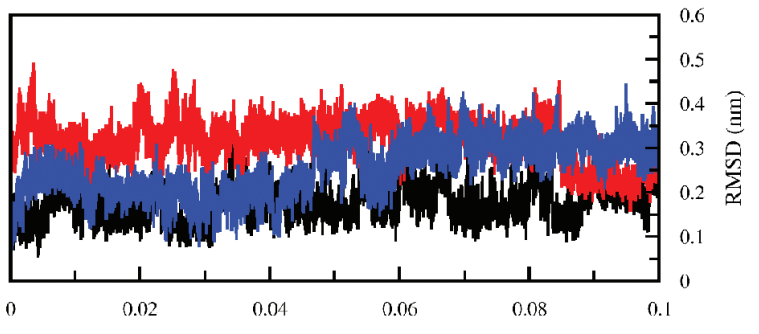

$\mathrm{F}$

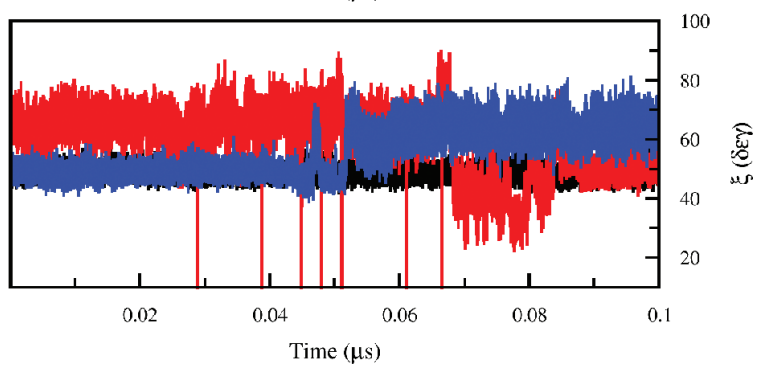

Figure 3 - MD analyses as a function of time in relation to the starting X-ray-derived model for System 1 (brown), System 2 (indigo), System 3 (black), System 4 (blue), System 5 (red), and System 6 (green) considering the following properties: root mean square deviation (RMSD) for entire protein (A) and (B), and for residues of C-terminal $\alpha$-helix (C) and (D). Average pseudo dihedral $\xi$ (i.e. the dihedral formed by 4 consecutive $\alpha$-carbon atoms Cai, $\mathrm{Cai}_{+1}, \mathrm{Cai}_{+2}$ and $\mathrm{Cai}_{+3}$ ) over residues of C-terminal $\alpha$-helix (E) and (F), for which the reference value for a $\alpha$-helical content is around $45^{\circ}$ (see Section 3.2 for further details).

\section{StRUCTURAL FLUCTUATION}

While the RMSD data presented in Figure 2 present a global perspective on the protein conformational behavior during the performed simulations, they lack resolution at the residue level. To overcome this limitation, the flexibility and helical content of EqtxII and StnII as a function of both time and residue numbers were evaluated by root mean square fluctuation (RMSF) and ellipticity at 222 nm (Figure 5), as previously described (Pol-Fachin et al. 2009, Terra et al. 2007, Verli et al. 2007, Verli and Guimarães 2005). The respective plots were drawn from the compilation of average data at every 200 ps of trajectory.
These analyses revealed that upon acidification the loop regions connecting strands $\beta 5$ and $\beta 6$ and strands $\beta 8$ and $\beta 9$, presented increased flexibility in EqtxII and decreased flexibility in StnII (Figures $5 \mathrm{~B}$ and $5 \mathrm{D}$, respectively). On the other hand, the flexibility observed for the protein N-terminal region for both EqtxII and StnII (Figure 5) was similar during their trajectories in acidic and physiological solutions.

Such similar flexibility in acidic condition was also observed when comparing the two proteins, including increased flexibility of the loop between strands $\beta 6$ and $\beta 7$ (Figures 5B and 5D, respectively). It is noteworthy that the loop between strands $\beta 6$ and $\beta 7$ and the beginning of strand $\beta 7$, correspond to the 

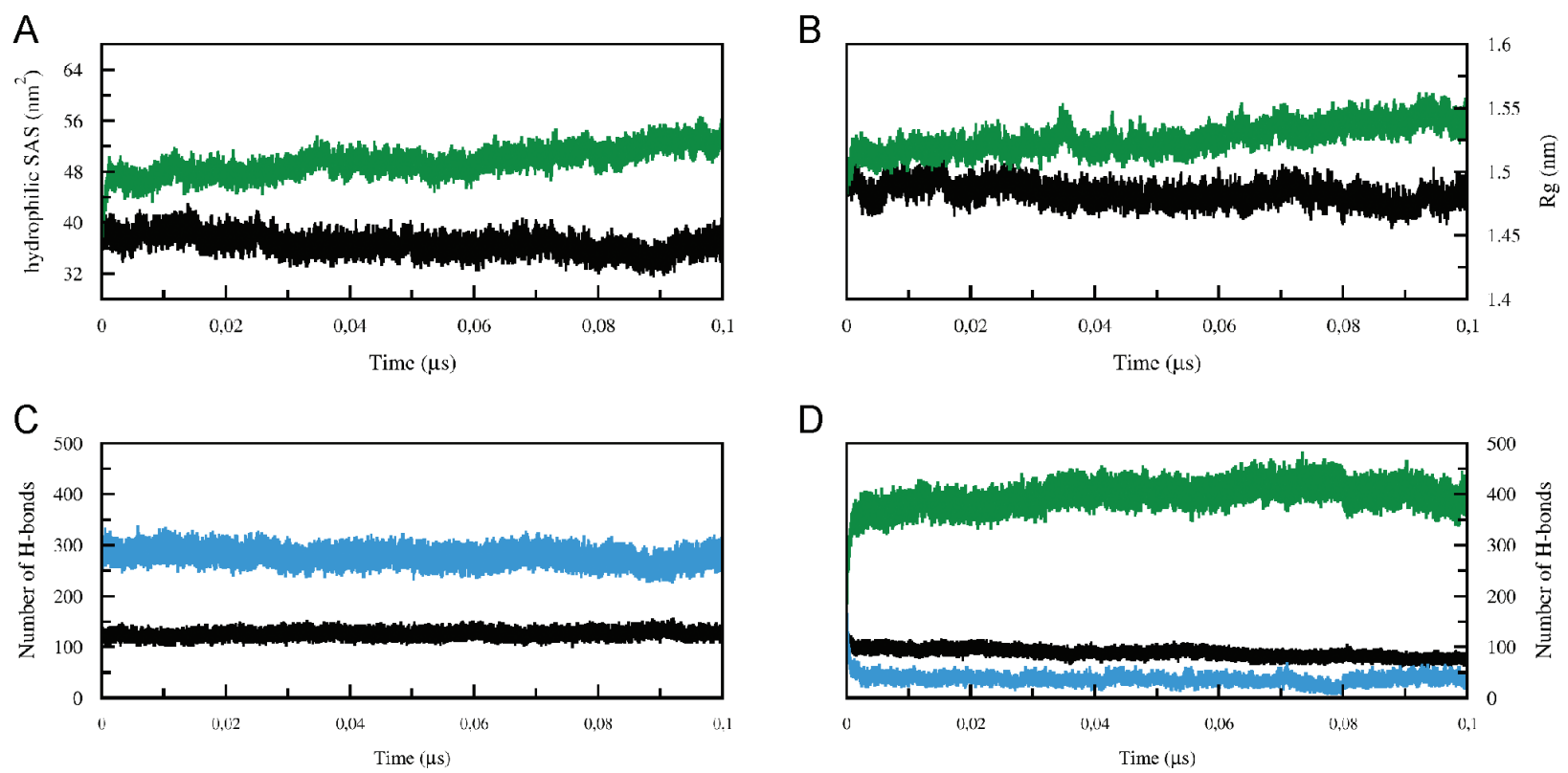

Figure 4 - MD analyses as a function of time in relation to the starting X-ray-derived structure considering the: (A) hydrophilic solventaccessible surface (SAS) and (B) gyration radious (Rg) for Systems 3 (black curve) and 6 (green curve). Additionally, the number of protein-protein (black curve) and protein-water (light blue curve) hydrogen bonds is presented for Systems 3 (C) and 6 (D), as well as the protein-urea hydrogen bonds (green curve) in System 6 (D).

TRP-rich region (Trp112, Trp116, Trp117 in EqtxII and Trp110, Trp114, Trp115 in StnII), an essential segment for membrane interaction (Anderluh et al. 2005, Hong et al. 2002). Furthermore, this loop is located in the vicinity of the phosphocholine binding site (Ser52, Val85, Ser103, Pro105, Tyr111, Tyr131, Tyr135, Tyr136 in StnII, and Ser54, Val87, Ser105, Pro107, Tyr113, Tyr133, Tyr137, Tyr138 in EqtxII). Experimental data support that acidic solutions are capable of increasing the interaction between StnII and EqtxII with hydrophobic probes (Álvarez et al. 2001, Martínez et al. 2001, Malavasic et al. 1996), and that some pore-forming proteins may undergo partial unfolding triggered by membrane surfaces (Parker and Feil 2005, Bychkova et al. 1996, van der Goot et al. 1991). Previous works (Ulrih et al. 2004, Mancheño et al. 2001) also indicate that acidic conditions may be employed in the study of EqtxII and StnII to mimic the conformational modifications induced by the membrane surface, suggesting that such conditions may induce conformational changes suitable for molecular target recognition.
Considering that the analyses of RMSD and RMSF for EqtxII (Systems 1-2) and StnII (Systems 3-4) pointed to modifications in the secondary structure content and flexibility on the C-terminal $\alpha$-helix of these toxins, its $\alpha$-helical content was characterized through ellipticity. Ellipticity is defined as the percentage of time in which the residues present a helical nature as a function of time and residue numbers (Hirst and Brooks 1994) (Figure 5). Accordingly, the increased flexibility in this region seems to be related to the stability of its helical content over the simulation time for EqtxII (Figures 5B and 5H, Figures 6A and 6B) and for StnII (Figures 5D and 5J). In addition, our results corroborate synchrotron radiation $\mathrm{CD}$ analysis for EqtxII (Miles et al. 2008), indicating that this secondary structure may change in solution (Figures $5 \mathrm{G}$ and $5 \mathrm{H}$ ), although in acidic solutions a high degree of conformational instability in the C-terminal $\alpha$-helix may be observed (Figure 6B).

When the last frame of StnII, simulated at $\mathrm{pH}$ 3.0 is modified to $\mathrm{pH} 7.0$ (i.e. is, a return of StnII to physiological $\mathrm{pH}$ ), the beginning of the reversion 

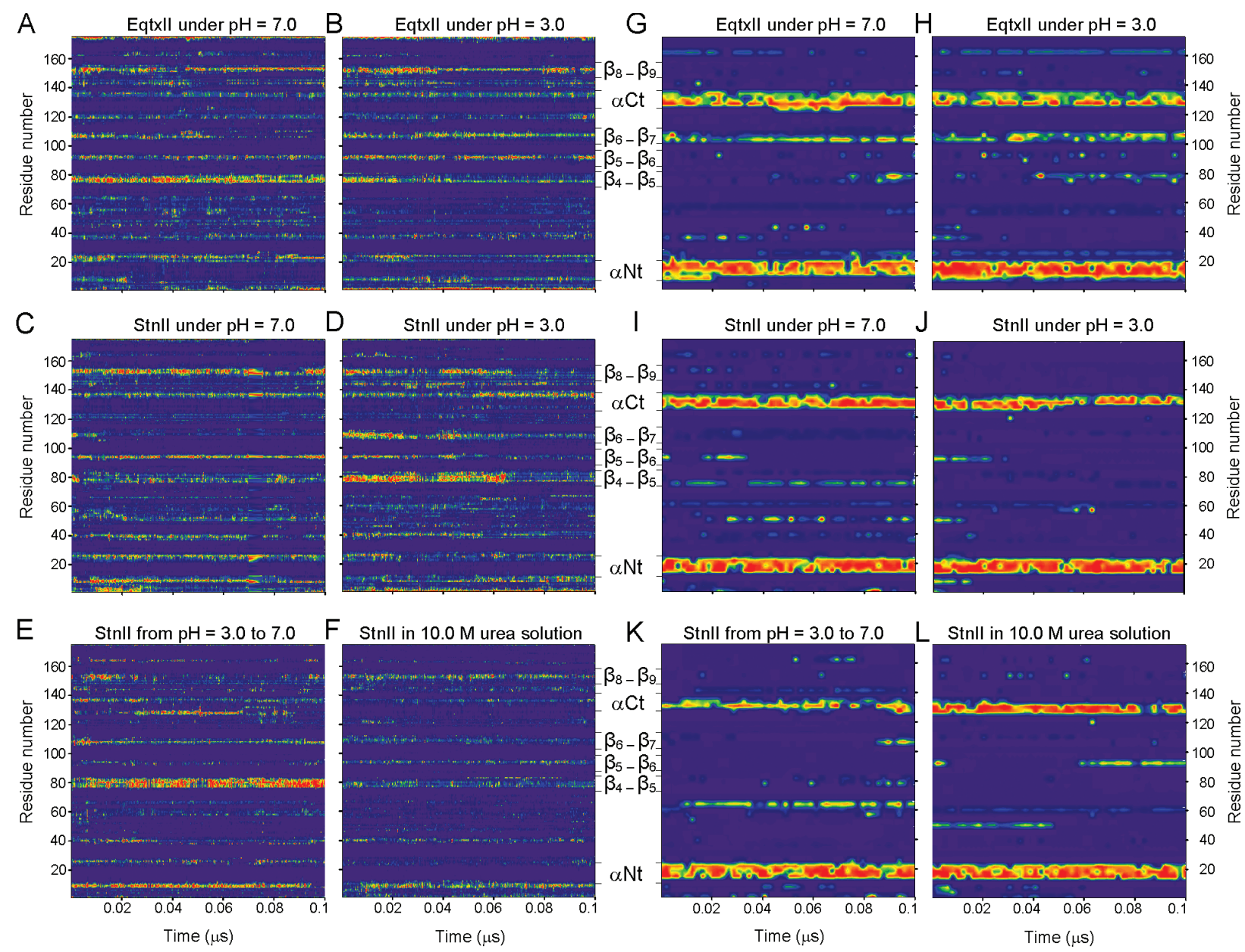

Figure 5 - All-atom RMSF from 0.06 to $0.14 \mathrm{~nm}$ for Systems 1 (EqtxII under $\mathrm{pH}=7.0, \mathrm{~A}), 2$ (EqtxII under $\mathrm{pH}=3.0, \mathrm{~B}), 3$ $(\mathrm{StnII}$ under $\mathrm{pH}=7.0, \mathrm{C}), 4(\mathrm{StnII}$ under $\mathrm{pH}=3.0, \mathrm{D}), 5(\mathrm{StnII}$ under $\mathrm{pH}=7.0$ starting from the last frame of the simulation at $\mathrm{pH}=3.0, \mathrm{E}$ ), and 6 (StnII in $10.0 \mathrm{M}$ urea solution, F); and ellipticity from 0 to $80 \%$ at $222 \mathrm{~nm}$ (percentage of time in which the residues present a helical nature) for Systems $1(\mathrm{G}), 2(\mathrm{H}), 3(\mathrm{I}), 4(\mathrm{~J}), 5(\mathrm{~K})$, and $6(\mathrm{~L})$. Both analyses range from blue to red according with the increase in flexibility or helical content.

process is observed, with a consequent decrease in flexibility and increase in helical content, close to 0.1 $\mu$ s of simulation (Figures 5E, 5K and Figure 7). Such behavior suggests that acidic environments may be able to induce partially unfolded states for StnII and EqtxII, mainly in the C-terminal $\alpha$-helix. This observation agrees with the NMR structure of EqtxII, which was obtained in acidic solution and is partially unfolded when compared to the crystal structures of actinoporins (Figure 1). Considering the physicalchemical characteristic (e.g. dielectric constant, $\mathrm{pH}$ ) and complex composition (e.g. lipids, proteins, carbohydrates) at the membrane surface (Konkul 2009, Parker and Feil 2005, Sui 2000), our results may be complementary to a previous publication (Lam et al. 2009) that presented MD simulations for EqtxII in DMPC membrane environment.

In opposition to its behavior in acidic medium, the simulation of StnII in a $10.0 \mathrm{M}$ urea solution (System 6), presented lower flexibility for the entire protein (Figure 5F). This may be the reason for the small deviation in RMSD and radius of gyration from the starting structure (green curve in Figure 2A and Figure 4B). Furthermore, a comparison of 

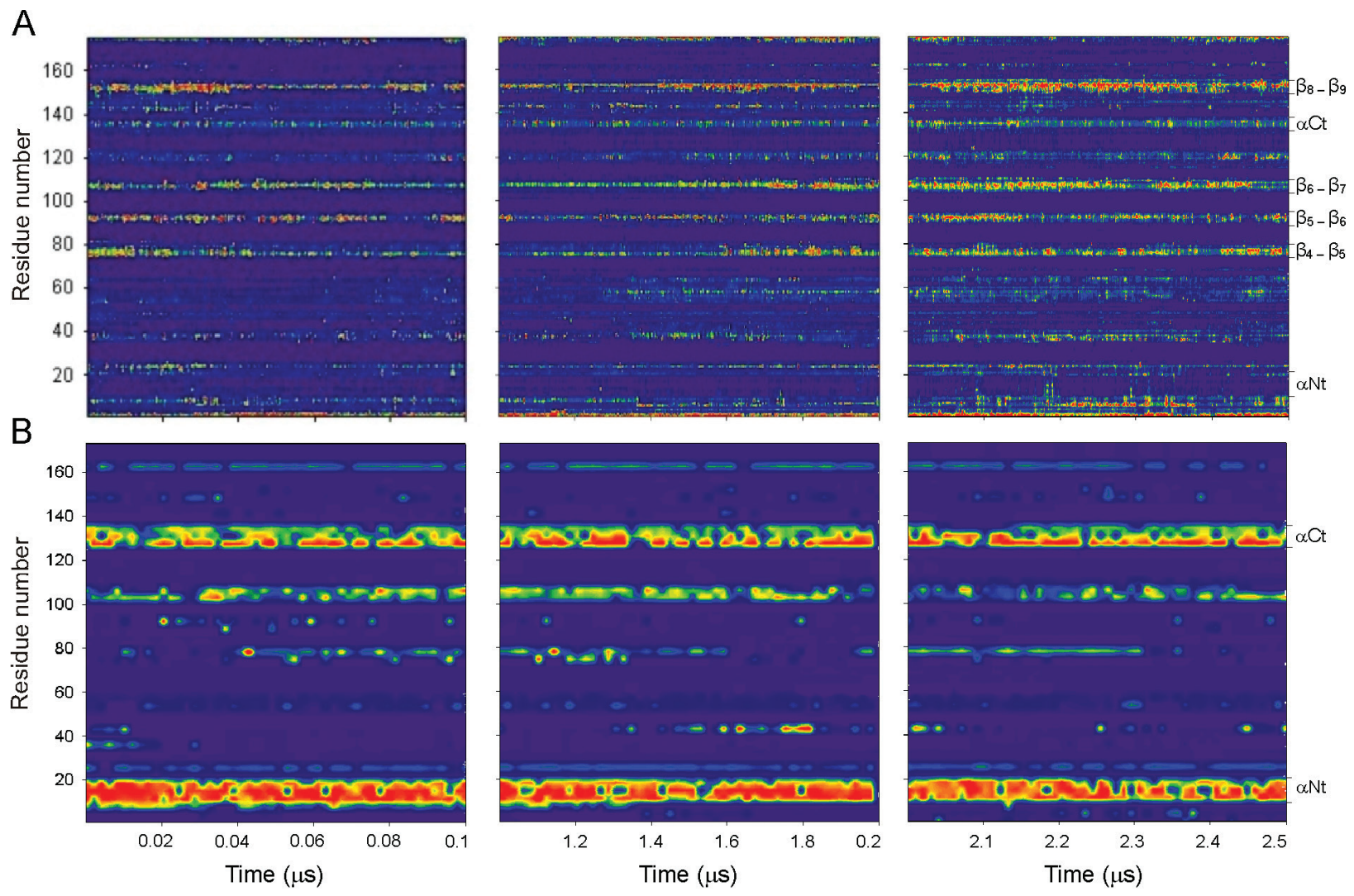

Figure 6 - (A) All-atom root mean square fluctuation (RMSF) from 0.06 to $0.14 \mathrm{~nm}$ for EqtxII in acidic solution (System 2) over the $0.25 \mu$ s simulation as a function of both time and residue numbers are presented together with its corresponding (B) ellipticity from 0 to $80 \%$ at $222 \mathrm{~nm}$ (percentage of time in which the residues present a helical nature). Both analyses range from blue to red according with the increase in flexibility or helical content.

radial distribution function of the solvent around the protein, when in neutral condition and in 10.0 $\mathrm{M}$ urea solution (Figures 2E and 2F, respectively), indicates that the water solvation shells of StnII are influenced by the high urea concentration (black curve in Figure 2F). Such process is accompanied by an increase of its hydrophilic SAS in relation to the starting X-ray-derived structure (Figure 4A), as well as by an increased number of hydrogen bond interactions between hydrophilic residues and the urea molecules that accumulate around them (green curve in Figures 2F, 4D, and 8). Such increased protein-solvent interaction may explain the lower flexibility on System 6 in comparison to the no-urea Systems.
STRUCTURAL REASONS FOR THE LACK OF STNII HeMOLYTIC ACTIVITY IN UREA SOLUTION

The conformational changes caused by different denaturation conditions (i.e. pre-incubation and incubation in extremely acidic and alkaline solutions, increasing concentration of strong denaturant agents like guanidine hydrochloride and urea) were used in the search for partially unfolded states of EqtxII and StnII. Such states were used as proxies for the pore formation in lipid membranes and red blood cells (Álvarez et al. 1998, 2001, Martínez et al. 2001, Malavasic et al. 1996, Belmonte et al. 1993). Accordingly, experimental results indicate that the conformational modifications induced by changing the $\mathrm{pH}$ are less preeminent than those 


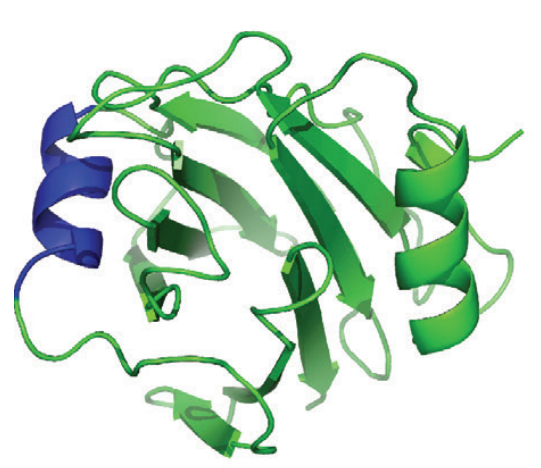

Stnll under $\mathrm{pH}=7.0(0.1 \mu \mathrm{s})$

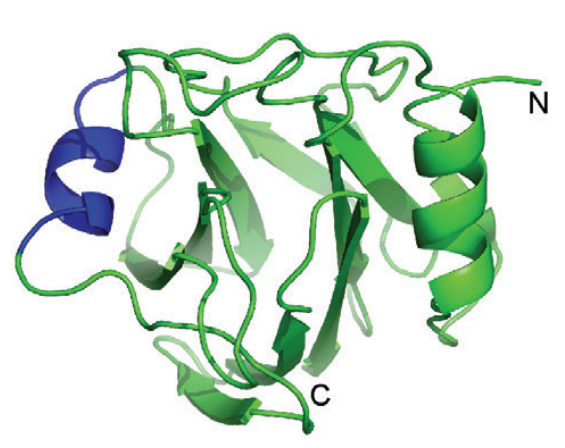

Stnll under $\mathrm{pH}=3.0(0.2 \mu \mathrm{s})$

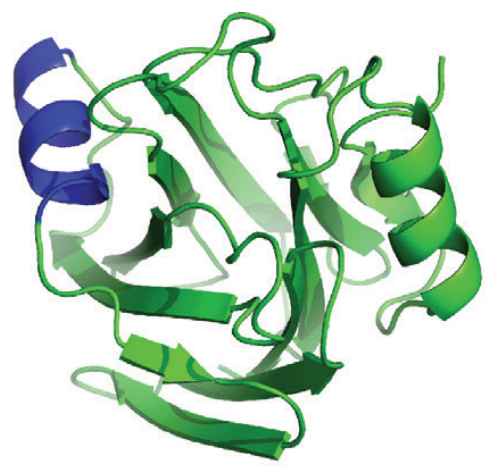

Stnll from $\mathrm{pH}=3.0$ to $7.0(0.3 \mu \mathrm{s})$

Figure 7 - Conformational transitions of StnII over $0.3 \mu$ s MD simulation as a function of solution $\mathrm{pH}$. The helical content was analyzed employing the progression of the average pseudo dihedral $\xi$, that is, the dihedral formed by 4 consecutive $\alpha$-carbon atoms

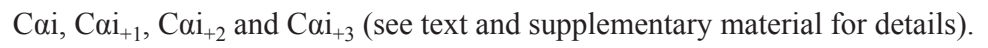

caused by urea (Álvarez et al. 2001, Malavasic et al. 1996). In addition, most of the experimental data associated with these modifications were presented by fluorescent measurements, for which both EqtxII and StnII had their structures affected by an increased exposure in their Trp residues to aqueous solution (Álvarez et al. 2001, Malavasic et al. 1996). Such exposure reduced the hemolytic activity of StnII without major modifications in its secondary structure content (Martínez et al. 2001).

Our results in the MD simulation of StnII in 10.0 M urea solution (System 6) are in agreement with previous far-UV CD spectrum (Martínez et al. 2001), since the obtained trajectory did not present major changes in the protein secondary structure content. Our results also agree with fluorescence data, as the interaction between theses residues and solution molecules in System 6 was increased almost two-fold when compared to others systems (Table I). Furthermore, when this analysis was performed for residues encompassing the phosphocholine binding site, a similar behavior was observed for Pro105, Tyr111, Tyr135 and Tyr136 (Table I). Since Tyr135 and Tyr136 residues compose the C-terminal $\alpha$-helix of StnII, this observation may be related to the increased deviation previously present in Figure 2C (green curve).
Analyses to verify if protein residues were preferentially interacting with urea molecules were also performed by measuring the interaction energy between protein residues and solution molecules. The results obtained (Table II) are in agreement with the data presented in Figure $2 \mathrm{~F}$ and Figure 4D, as illustrated in Figure 8, suggesting that the molecular target recognition by StnII may not be favored in this condition.

Taking into account the necessary interaction with the membrane surface and the need for flexibility in the action mechanism of actinoporins, it seems that urea may modulate StnII hemolytic activity by hampering its ability to interact with membrane surfaces. It may also cause molecular rigidity, which may impair the conformational changes associated with pore formation.

\section{CONCLUSIONS}

In the current work, we performed a series of MD simulations of actinoporins EqtxII and StnII in different solution conditions in order to support the characterization of protein structure, conformation and dynamics, according to environmental conditions at the atomic level.

The solvation effects caused by urea may have a role in modulating hemolytic activity of StnII, as suggested by the calculations presented in this work. 
TABLE I

Interaction energy analysis between Trp and phosphocoline binding site residues of actinoporins and solution molecules present in each condition.

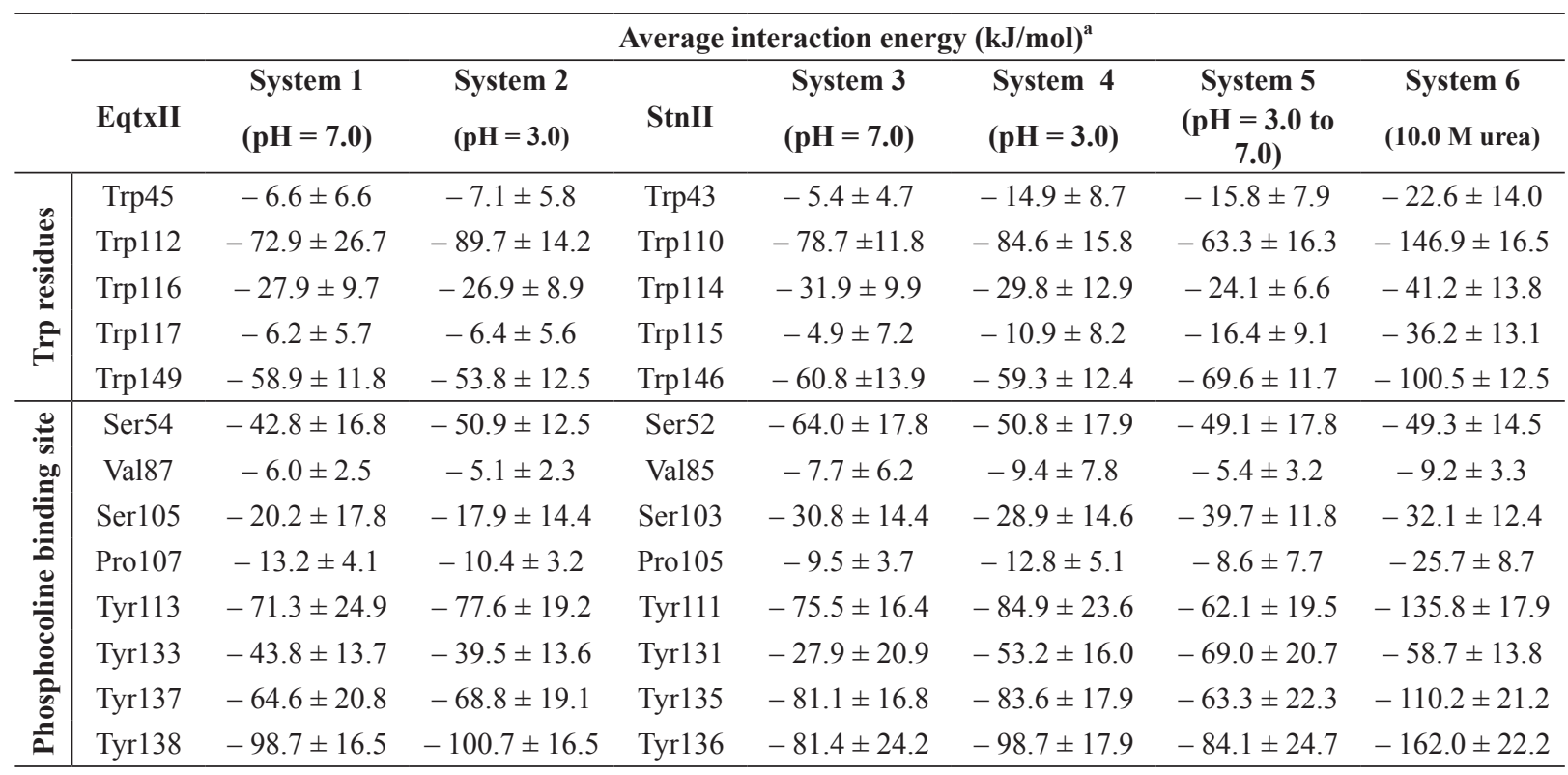

${ }^{\mathrm{a}}$ Average values from the sum of Coulomb and Lennard-Jones components over the $0.1 \mu$ s MD simulation.

TABLE II

Interaction energy analysis between Trp and phosphocoline binding site residues of StnII and solution molecules present in a $10.0 \mathrm{M}$ urea solution.

\begin{tabular}{|c|c|c|c|c|}
\hline \multicolumn{5}{|c|}{ Average interaction energy $(\mathrm{kJ} / \mathrm{mol})$} \\
\hline & \multirow{2}{*}{ StnII } & \multicolumn{3}{|c|}{ System 6} \\
\hline & & water & Urea & solution \\
\hline \multirow{5}{*}{ 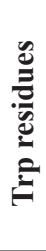 } & Trp43 & $-1.7 \pm 3.1$ & $-20.9 \pm 13.9$ & $-22.6 \pm 14.0$ \\
\hline & $\operatorname{Trp} 110$ & $-27.4 \pm 13.1$ & $-119.4 \pm 22.0$ & $-146.9 \pm 16.5$ \\
\hline & $\operatorname{Trp} 114$ & $-4.8 \pm 5.2$ & $-36.4 \pm 14.1$ & $-41.2 \pm 13.8$ \\
\hline & Trp115 & $-1.7 \pm 3.1$ & $-35.6 \pm 13.5$ & $-36.2 \pm 13.1$ \\
\hline & Trp146 & $-11.7 \pm 10.5$ & $-88.8 \pm 16.9$ & $-100.5 \pm 12.5$ \\
\hline \multirow{8}{*}{ 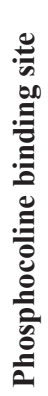 } & Ser52 & $-10.1 \pm 13.3$ & $-39.2 \pm 15.5$ & $-49.3 \pm 14.5$ \\
\hline & Val85 & $-1.2 \pm 1.6$ & $-7.9 \pm 3.2$ & $-9.2 \pm 3.3$ \\
\hline & Ser103 & $-11.5 \pm 15.2$ & $-20.6 \pm 14.0$ & $-32.1 \pm 12.4$ \\
\hline & Pro105 & $-1.2 \pm 1.8$ & $-24.4 \pm 9.1$ & $-25.7 \pm 8.7$ \\
\hline & Tyr111 & $-31.2 \pm 20.5$ & $-104.5 \pm 22.0$ & $-135.8 \pm 17.9$ \\
\hline & Tyr131 & $-15.8 \pm 17.1$ & $-42.9 \pm 20.2$ & $-58.7 \pm 13.8$ \\
\hline & Tyr135 & $-27.0 \pm 19.3$ & $-83.2 \pm 26.4$ & $-110.2 \pm 21.2$ \\
\hline & Tyr136 & $-36.9 \pm 20.9$ & $-125.1 \pm 28.2$ & $-162.0 \pm 22.2$ \\
\hline
\end{tabular}

${ }^{a}$ Average values from the sum of Coulomb and Lennard-Jones components over the $0.1 \mu$ s MD simulation. 


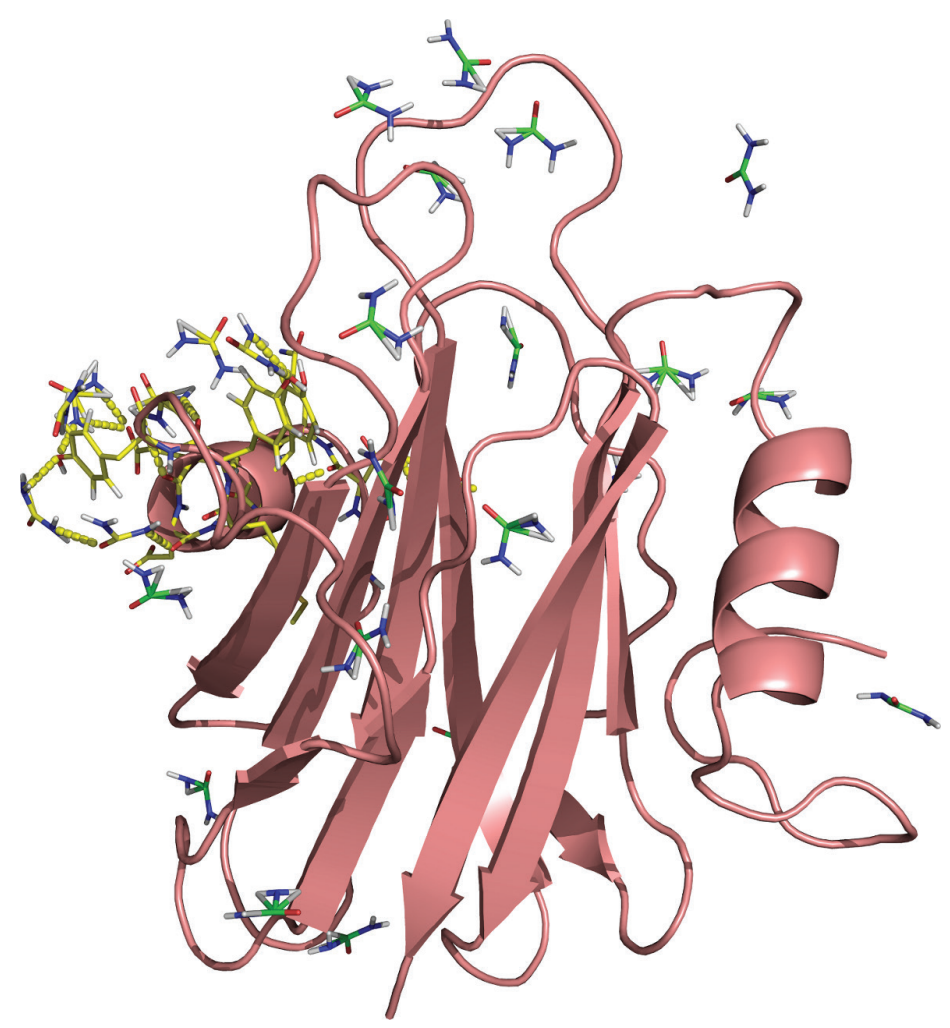

Figure 8 - Illustration of the of hydrogen bond interactions between hydrophilic residues in the C-terminal $\alpha$-helix of StnII (i.e. Tyr135 and Tyr136) and urea molecules that accumulates around it.

Such effects seem to be brought about with little to no loss in secondary structure content. Additionally, some pore-forming proteins underwent partial unfolding triggered by a local acid $\mathrm{pH}$ (Parker and Feil 2005, Bychkova et al. 1996, van der Goot et al. 1991). Thus, our results agree with previous studies (Ulrih et al. 2004, Mancheño et al. 2001) indicating that an acid condition can be employed in the study of EqtxII and StnII to mimic the effect of such acidic condition. In this way, our results show that during the simulations in acidic condition the folded structure of StnII undergoes a conformational modification, resembling the unfolded NMR conformation of EqtxII. Such partially unfolding was observed to be reversible and centered in functionally important regions of these proteins. There are indications that a more intricate behavior is required for these proteins to be active, including loop disorder and charge interactions for membrane contact, along with motif conservation and long-distance conformational rearrangements for proper pore formation and activity (Bakrac and Anderluh 2010, Pardo-Cea et al. 2011, García- Linares et al. 2013, 2014). Nonetheless, acidic medium models are still employed to study conformational changes in actinoporins, and our work presented atom-level observations regarding the conformational behavior of these proteins.

Altogether, it may be expected that a deeper comprehension of these phenomena could contribute to future explorations of biological properties of actinoporins and to the rational design of new bioactive compounds.

\section{ACKNOWLEDGMENTS}

We thank the Fundação de Amparo à Pesquisa do Estado do Rio Grande do Sul (FAPERGS), the Conselho Nacional de Desenvolvimento Científico e Tecnológico (CNPq), Ministério da Ciência, 
Tecnologia e Inovação (MCTI), and the Coordenação de Aperfeiçoamento de Pessoal de Nível Superior (CAPES), Ministério da Educação, Brasília, DF, Brazil, for their financial support and fellowships.

\section{RESUMO}

Actinoporinas constituem uma família de proteínas formadoras de poros com atividade hemolítica. A base estrutural para tal atividade parece depender do seu enovelamento correto, especialmente em torno de algumas regiões funcionais, incluindo um sítio de ligação a fosfocolina, uma região rica em resíduos de triptofano e o amino-terminal. Adicionalmente, diferentes condições de solvatação são reconhecidamente capazes de influenciar a formação de poros por actinoporinas, como observado para Sticolisina II (StnII) e Equinatoxina (EqtxII). Neste contexto, o presente trabalho visa caracterizar a influência de diferentes soluções no comportamento conformacional dessas proteínas, por meio de simulações de dinâmica molecular. Os dados obtidos fornecem insights estruturais sobre a dinâmica das actinoporinas em solução, caracterizando seu comportamento conformacional em nível atômico, de acordo com dados experimentais previamente obtidos para as atividades hemolíticas de StnII e EqtxII.

Palavras-chave: Actinoporinas, GROMACS, dinâmica molecular, proteínas formadoras de poros.

\section{REFERENCES}

Álvarez C, Lanio Me, Tejuca M, Martínez D, Pazos F, CAMPOS AM, ENCINAS MV, PRETIÑES T, SCHREIER S AND LISSIEA. 1998. The role of ionic strength on the enhancement of the hemolytic activity of sticholysin I, a cytolysin from Stichodactyla helianthus. Toxicon 36: 165-178.

Álvarez C, Mancheño JM, Martínez D, TeJuCA M, Pazos F AND LANIO ME. 2009. Sticholysins, two pore-forming toxins produced by the Caribbean Sea anemone Stichodactyla helianthus: their interaction with membranes. Toxicon 54: 135-1147.

Álvarez C, Pazos IF, Lanio ME, Martínez D, Schreier S CASAllanovo F, CAMOS AM AND Lissi E. 2001. Effect of $\mathrm{pH}$ on the conformation, interaction with membranes and hemolytic activity of sticholysin II, a pore forming cytolysin from the sea anemone Stichodactyla helianthus. Toxicon 39: 539-553.
ANDERluh G AND MAČEK P. 2002. Cytolytic peptide and protein toxins from sea anemones (Anthazoa: Actiniaria). Toxicon 40: 111-124.

Anderluh G, Pungercar J, Krizaj I, Strukelu B, Gubensek F AND MAČEK P. 1997. N-terminal trucation mutagenesis of equinatoxin II, a pore-forming protein from the sea anemone Actinia equina. Protein Eng 10: 751-755.

ANDERluh G, RAZPotNiK A, PODLESEK Z, MAČEK P, SEPAROVIC F AND NORTON RS. 2005. Interaction of the eukaryotic pore-forming cytolysin equinatoxin II with model membranes: ${ }^{19} \mathrm{~F}$ NMR studies. J Mol Biol 347: 27-39.

AthanAsiadis A, ANDERLUH G, MAČEK P AND TURK D. 2001. Crystal structure of the soluble form of equinatoxin II, a pore-forming toxin from the sea anemone Actinia equina. Structure 9: 341-346.

BAKRAC B AND ANDERLUH G. 2010. Molecular mechanism of sphingomyelin-specific membrane binding and pore formation by actinoporins. Adv Exp Med Biol 677: 106-115.

Belmonte G, Pederzolli C, Macek P and Menestrina G. 1993. Pore formation by the sea anemone cytolysin equinatoxin II in red blood cells and model lipid membranes. J Membr Biol 131: 11-22.

Berendsen HJC, Postman JPM, DinOla A AND HaAK JRJ. 1984. Molecular-dynamics with coupling to an external bath. Chem Phys 81: 3684-3690.

Berendsen HJC, Postman JPM, VAN GUNSTEREN WF AND HERMANS J. 1981. Interaction models for water in relation to protein hydration. In: PULLMAN B (Ed), Intermolecular forces, Reidel: Dordrecht, Netherlands, p. 331-342.

Bychkova VE, Dujsekina AE, Klenin SI, TikTopulo EI, UVERSKY VN AND PTITSYN OB. 1996. Molten globulelike state of cytochrome $\mathrm{c}$ under conditions simulating those near the membrane surface. Biochemistry 35: 6058-6063.

Casallanovo F ET AL. 2006. Model peptides mimic the structure and function of the N-terminus of the poreforming toxin sticholysin II. Biopolymers 84: 169-180.

DARden T, York D AND PEDERSEN LJ. 1993. Particle mesh Ewald - an $N \log (\mathrm{N})$ method for Ewald sums in large systems. Chem Phys 98: 10089-10092.

DE GROOT BL AND GRUBMÜLlER H. 2001. Water permeation across biological membranes: mechanism and dynamics of aquaporin-1 and GlpF. Science 294: 2353-2357.

DE WitTe RS AND SHAKHNOVICH EJ. 1994. Pseudodihedrals: simplified protein backbone representation with knowledgebased energy. Protein Sci 3: 1570-1581.

Delano WL. 2002. The Pymol Molecular Graphics System. Delano Scientific: San Carlos, USA.

García-Linares S, Castrillo I, BRUiX M, MenÉndez M, Alegre-Cebollada J, MartíneZ-DEl-Pozo Á AND GAVILANES JG. 2013. Three-dimensional structure of the actinoporin sticholysin I. Influence of long-distance effects on protein function. Arch Biochem Biophys 532: $39-45$ 
GARCíA-LinARES S, RichMOND R, GARCÍA-MAYORAL MF, Bustamante N, BRUIX M, GaVILANES JG AND MARTínEZDEL-POZO A. 2014. The sea anemone actinoporin (ArgGly-Asp) conserved motif is involved in maintaining the competent oligomerization state of these pore-forming toxins. FEBS J 281: 1465-1478.

GueX N AND PeITSCH MC. 1997. Swiss-model and the Swis Pdb Viewer: an environment for comparative protein modeling. Electrophoresis 18: 2714-2723.

Hess B, BekKer H, Berendsen JC and FraAiJe JGEM. 1997. LINCS: a linear constraint solver for molecular simulations. J Comput Chem 18: 1463-1472.

Hinds MG, Zhang W, Anderluh G, Hansen PE AND NORTON RG. 2002. Solution structure of the eukaryotic pore-forming cytolysin equinotoxin II: Implications for pore formation. J Mol Biol 315: 1219-1229.

HIRST JD AND BROOKS CL III. 1994. Helicity, circular dichroism and molecular dynamics of protein. J Mol Biol 243: 173-178.

Hong Q, Gutiérrez-Aguirre I, Barlič A, Malovrh P, Kristan K, PodleseK Z, MAČEK P, TURK D, GonZÁleZMAÑAS JM, LAKEY JH AND ANDERLUH G. 2002. Twostep membrane binding by equinatoxin II, a pore-forming toxin from the sea anemone, involves an exposed aromatic cluster and a flexible helix. J Biol Chem 277: 41916-41924.

Huerta V, Morera V, Guanche Y, Chinea G, Gonzalez LJ, Betancourt L, Martínez D, Álvarez C, Lanio ME AND BESADA V. 2001. Primary structure of two cytolysin isoforms from Stichodactyla helianthus differing in their hemolytic activity. Toxicon 39: 1253-1256.

HumPhreY W, DALKE A AND SCHULTEN K. 1996. VMD - Visual Molecular Dynamics. J Mol Graph Model 14: 33-38.

IUPAC-IUB COMMISSION ON BIOCHEMICAL NOMENCLATURE. 1970. Abbreviations and symbols for description of conformation of polypeptides chains. J Mol Biol 52: 1-17.

KONKUL A. 2009. Lipid models for united-atom molecular dynamics simulations of proteins. J Chem Theory Comput 5: 615-626.

Kristan CK, PoDlesek Z, HoJnIK V, GutiérReZ-Aguirre I, GuNČAR G, TuRK D, GONZÁlEZ-MAÑAS JM, LAKEY JH AND MAČEK P. 2004. Pore formation by equinatoxin, a eukaryotic pore-forming toxin, requires a flexible $\mathrm{N}$-terminal region and a stable $\beta$-sandwich. J Biol Chem 279: 46509-46517.

Kristan CK, Viero G, Dalla Serra M, MačeK P AND ANDERLUH G. 2009. Molecular mechanism of pore formation by actinoporins. Toxicon 54: 1125-1134.

LAM YH, Hung A, Norton RS, Separovic F AND Watts A. 2009. Solid-state NMR and simulation studies of equinatoxin II N-terminus interaction with lipid bilayers. Proteins 78: 858-872.

LANIO ME ET AL. 2001. Purification and characterization of two hemolysins from Stichodactyla Helianthus. Toxicon 39: 187-194.

LASKOWSKI A, MACARTHUR MW, MOSS DS AND THORNTON JM. 1993. PROCHECK: a program to check the steochemical quality of protein structures. J Appl Crystallogr 26: 283-291.
Malavasic M, Poklar N, MaceK P And Vesnaver G. 1996. Fluorescence studies of the effect of $\mathrm{pH}$, guanidine hydrochloride and urea on equinatoxin II conformation. Biochim Biophys Acta 1280: 65-72.

Mancheño JM, De Los Ríos V, Del Pozo AM, Lanio ME, OÑADERRA M AND GAVILANES JG. 2001. Partially folded states of the cytolytic protein Sticholysin II. Biochim Biophys Acta 545: 122-131.

Mancheño JM, Martin-Benito J, Martinez-Ripoll M, Gavilanes JG And Hermanoso JA. 2003. Crystal and electron microscopy structures of sticholysin II actinoporin reveal insights into the mechanism of membrane pore formation. Structure 11: 1319-1328.

Martínez D, Campos AM, Pazos F, Álvarez C, Lanio ME, Casallanovo F, Schreier S, Salinas RK, Vergara C AND LISSI E. 2001. Properties of St I and St II, two isotoxins isolated from Stichodactyla helianthus: a comparison. Toxicon 39: 547-1560.

Miles AJ, Drechsler A, Kristan K, ANDERluh G, Norton RS, Wallace BA AND Separovic F. 2008. The effects of lipids on the structure of the eukaryotic cytolysin equinatoxin II: a synchrotron radiation circular dichroism spectroscopic study. Biochim Biophys Acta 1778: 2091-2096.

NORTON RS. 2009. Structures of sea anemones toxins. Toxicon 54: 1075-1088.

Pardo-Cea MA, Castrillo I, Alegre-Cebollada J, MARTínEZ-DEL-POZO Á, Gavilanes JG AND BRUIX M. 2011. Intrinsic local disorder and a network of chargecharge interactions are key to actinoporin membrane disruption and cytotoxicity. FEBS J 278: 2080-2089.

PARKER MW AND FEIL SC. 2005. Pore-forming protein toxins: from structure to function. Prog Biophys Mol Biol 88: 91-142.

Poklar N, Lah J, SAlobir M, MačEK P AND VesnaVer G. 1997. $\mathrm{pH}$ and temperature-induced molten globule-like denatured states of equinatoxin II: a study by UV-melting, DSC, Far- and Near-UV CD spectroscopy, and ANS flurescence. Biochemistry 36: 14345-14352.

Pol-FAChIN L, FERnANDES CL AND VerLi H. 2009. GROMOS96 43a1 performance on the characterization of glycoprotein conformational ensembles through molecular dynamics simulations. Carbohydr Res 344: 491-500.

Rocco AG, Mollica L, RicchiUto P, BAptista AM, GIANAZZA E AND EBERINI I. 2008. Characterization of the protein unfolding processes induced by urea and temperature. Biophys J 94: 2241-2251.

SUI S. 2000. Membrane-induced conformational changes of proteins. Adv Colloid Interface Sci 85: 257-267.

Tejuca M, Anderluh G AND Dalla Serra M. 2009. Sea anemone cytolysins as toxic components of immunotoxins. Toxicon 54: 1206-1214.

TERra RMS, GuIMARÃes JA AND VerLi H. 2007. Structural and functional behavior of biologically active monomeric melittin. J Mol Graph Model 25: 767-727.

ULRIH NP, ANDERLUH G, MACEK P AND CHALIKIAN TV. 2004. Salt-induced oligomerization of partially folded intermediates of equinatoxin II. Biochemistry 43: 9536-9545. 
VAN Der Goot FG, GonZaLes-Manas JM, LAKEy JH AND PATTUS FA. 1991. 'molten-globule' membrane-insertion intermediate of the pore-forming . domain of colicin A. Nature 354: 408-410.

Van Der Spoel D, Lindahl E, Hess B, Groenhof G, Mark AE AND BERENDSEN HJC. 2005. GROMACS: fast, flexible and free. J Comput Chem 26: 1701-1718.

VANGUNSTERENWF,BILLETER SR,EISINGAA,HÜNENBERGER PH, KRÜEGER P, MARK AE, SCOTT WRP AND TIRONI IG. 1996. Biomolecular simulation: the GROMOS96 manual and user guide, Zurich: Vdf Hochschulverlag.
VERLI H, CALAZANS A, BRINDEIRO R, TANURI A AND GUIMARÃES JA. 2007. Molecular dynamics analysis of HIV-1 matrix protein: Clarifying differences between crystallographic and solution structures. J Mol Graph Model 26: 62-68.

VERLI H AND GUIMARÃES JA. 2005. Insights into the induced fit mechanism in antithrombin-heparin interactions using molecular dynamics simulations. J Mol Graph Model 24: 203-212. 